\title{
ANALISIS PENGARUH MOTIVASI KERJA DAN KEPUASAN KERJA TERHADAP KINERJA PEGAWAI DINAS TENAGA KERJA, TRANSMIGRASI DAN SOSIAL (DISNAKERTRANSOS )KEBUMEN DENGAN DISIPLIN KERJA SEBAGAI VARIABEL INTER VENING
}

\section{Parmin}

\begin{abstract}
This study aims to determine the effect of work motivation and job satisfaction on the performance and work discipline on employee performance. The study population was all civil servants in the department of labor and social transmigration Kebumen district . This study used census method . our data obtained by giving questioner to all respondents who totaled 47 people . the technique used in this analysis is the analysis of lane ( path analysis) with SPSS 18 for windows .

Statistical methods in this study include : validity, reliability, multicolinearity test, heterocedasticity test, normality test, multiple linear regression analysis, path analysis, $\mathrm{t}$ test, $\mathrm{F}$ and coefficient of determination.

The results showed that work motivation affect the work discipline, motivation affect the performance and job satisfaction affect the performance. labor discipline effect on performance and job satisfaction affect the working discipline with a value of $\mathrm{r}^{2}$ ( $\mathrm{R}$ square ) for structural equation $\mathrm{I}$ is $62.6 \%$ means that job satisfaction and motivation influence the working discipline at $62.6 \%$. the remaining $37.4 \%$ is influenced by factors beyond the research and structural equation II is $75.0 \%$ meaning that work motivation, job satisfaction and work discipline affect the performance of the remaining $25.0 \% 75.0 \%$ is affected by factors beyond the research.
\end{abstract}

\section{Key words: Work motivation, job satisfaction, work discipline, performane}

\section{PENDAHULUAN \\ Latar Belakang}

Motivasi kerja seseorang menentukan bagaimana kinerjanya. Menurut Winardi (dalam Nawawi, 2008:123), motivasi adalah suatu kekuatan potensial yang ada di dalam diri seseorang manusia, yang dapat dikembangkannya sendiri atau dikembangkan oleh sejumlah kekuatan luar yang pada intinya berkisar sekitar imbalan finansial dan imbalan non finansial yang dapat mempengaruhi hasil kinerjanya secara positif atau secara negatif, tergantung pada situasi dan kondisi yang dihadapi orang yang bersangkutan.

Kebutuhan dan kepuasan kerja yang tidak terpenuhi dapat berakibat berkurangnya semangat kerja untuk bekarja yang menyebabkan pekerjaan tidak terselesaikan dengan baik.Peranan pimpinan sangatlah penting untuk memberikan pengawasan dan motivasi untuk bekerja dengan semangat, pemimpin yang kurang memahami karakteristik masing-masing bawahan. Dengan 
memahami karakteristik individu maka akan dapat ditentukan pekerjaan yang sesuai dengan karakteristik masing-masing individu sehingga hasil kerja akan sesuai dengan harapan organisasi dan kinerja akan semakin baik.

\section{Rumusan Masalah}

Berdasarkan uraian diatas, maka masalah dalam penelitian ini adalah "Bagaimanakah pengaruh motivasi kerja dan kepuasan kerja terhadap kinerja pegawai Dinas Tenaga Kerja, Transmigrasi dan Sosial Kebumen (Disnakertransos) dengan disiplin kerja sebagai variabel intervening."

\section{Tujuan Penelitian}

Untuk mengetahui pengaruh motivasi kerja terhadapdisiplin kerjapegawai Dinas Tenaga Kerja, Transmigrasi dan Sosial (Disnakertransos) Kabupaten Kebumen. Untuk mengetahui pengaruh kepuasan kerja terhadapdisiplin kerjapegawai Dinas Tenaga Kerja, Transmigrasi dan Sosial (Disnakertransos) Kabupaten Kebumen. Untuk mengetahui pengaruh motivasi kerja terhadapkinerjapegawai Dinas Tenaga Kerja, Transmigrasi dan Sosial (Disnakertransos) Kabupaten Kebumen. Untuk mengetahui pengaruh kepuasan kerja terhadapkinerjapegawai Dinas Tenaga Kerja, Transmigrasi dan Sosial (Disnakertransos) Kabupaten Kebumen. Untuk mengetahui pengaruh disiplin kerja terhadapkinerjapegawai Dinas Tenaga Kerja, Transmigrasi dan Sosial (Disnakertransos) Kabupaten Kebumen. Untuk mengetahui pengaruh motivasi kerja dan kepuasan kerja terhadapkinerjapegawai Dinas Tenaga Kerja, Transmigrasi dan Sosial (Disnakertransos) Kabupaten Kebumen dengan disiplin kerja sebagai variabel intervening.

\section{Landasan Teori}

\section{Kinerja}

Kinerja menurut Veithzal Rivai (2006:309) merupakan hasil atau tingkat keberhasilan seseorang secara keseluruhan selama periode tertentu di dalam melaksanakan tugas dibandingkan dengan berbagai kemungkinan.

Manajemen kinerja menurut Bacal (Dharma, 2005:19) merupakan proses komunikasi yang berkesinambungan dan dilakukan dalam kemitraan antara seseorang dan atasan langsungnya. Menurut Anwar P. Mangkunegara (2000:45), kinerja merupakan tingkat keberhasilan seseorang secara keseluruhan selama periode tertentu dalam melaksanakan tugas.

\section{Motivasi Kerja}

Motivasi kata dasarnya adalah motif yang berarti dorongan, sebab alasanseseorang melakukan sesuatu. Dengan demikian motivasi berarti suatu kondisi yang mendorong atau menjadi sebab seseorang melakukan sesuatu kegiatan (Nawawi, 2008:47). Pemahaman terhadap motif yang mendasarinya, maka akan dapat memahami mengapa seseorang melakukan sesuatu.

Menurut Robbins (2006:52), motivasi merupakan kesediaan untuk mengeluarkan tingkat upaya yang tinggi untuk tujuan organisasi, yang dikondisikan oleh kemampuan upaya itu dalam memenuhi beberapa kebutuhan individual .

Menurut Winardi (dalam Nawawi, 2008:123), motivasi adalah suatu kekuatan potensial yang ada di dalam diri seseorang manusia, yang dapat dikembangkannya sendiri atau dikembangkan oleh sejumlah kekuatan luar yang pada intinya berkisar sekitar imbalan moneter dan imbalan nonmoneter yang dapat mempengaruhi hasil kinerjanya secara positif atau secara negatif, hal mana tergantung pada situasi 
dan kondisi yang dihadapi orang yang bersangkutan.

\section{Kepuasan Kerja}

Kepuasan kerja berhubungan erat dengan faktor sikap, sebagaimana dikemukakan oleh Tiffin (dalam Widayat, 2009:39), kepuasan kerja berhubungan dengan sikap dari karyawan terhadap pekerjaannya sendiri, situasi kerja, kerja sama antara pimpinan dan sesame karyawan. Selaras dengan itu Martoyo kepuasan kerja (job satisfaction) adalah keadaan emosional karyawan dimana terjadi ataupun tidak terjadi titik temu antara nilai balas jasa karyawan dari perusahaan atau organisasi dengan tingkat nilai balas jasa yang memang diinginkan oleh karyawan, baik yang berupa financial maupun yang nonfinancial.

Menurut Blum (As'ad, 2003:20) faktor-faktor yang memberikan kepuasan kerja adalah: a) faktor individual, meliputi: umur, kesehatan, watak dan harapan; b) faktor sosial meliputi: hubungan kekeluargaan, pandangan masyarakat, kesempatan berekreasi, kegiatan perserikatan pekerja, kebebasan berpolitik, dan hubungan bermasyarakat; c) faktor utama dalam pekerjaan, meliputi: upah, pengawasan, ketentraman kerja, kondisi kerja dan kesempatan untuk maju. Selain itu juga penghargaan terhadap kecakapan, hubungan sosial didalam pekerjaan, ketepatan dalam menyelesaikan konflik antar manusia, persaan diperlakukan adil, baik yang menyangkut pribadi maupun tugas.

\section{Disiplin Kerja}

Disiplin kerja adalah suatu alat yang digunakan para pimpinan untuk berkomunikasi dengan karyawan agar mereka bersedia untuk mengubah suatu perilaku serta sebagai suatu upaya untuk meningkatkan kesadaran dan kesediaan seseorang mentaati semua peraturan perusahaan dan norma-norma sosial yang berlaku . Definisi lain disiplin adalah suatu sikap, perbuatan untuk selalu mentaati tata tertib. Disiplin adalah suatu proses yang dapat menumbuhkan perasaan seseorang untuk mempertahankan dan meningkatkan tujuan organisasi secara obyektif, melalui kepatuhannya menjalankan peraturan organisasi (Rivai dalam Mangkunegara, 2000:144).

Disiplin kerja adalah suatu sikap, perilaku yang dilakukan secara sukarela dan penuh kesadaran serta keadaan untuk mengikuti peraturan yang telah ditetapkan perusahaan baik tertulis maupun tidak tertulis (Nitisemito, 2006:199).Perilaku tidak disiplin yang timbul merupakan cerminan dari persepsi negatif pegawai terhadap kontrol yang dilakukan oleh perilaku pimpinan.Sebaliknya perilaku disiplin seorang karyawan yang timbul merupakan cerminan dari persepsi positif terhadap kontrol atasan atau pimpinan. Terkadang disiplin merupakan suatu proses yang negatif, yaitu suatu yang memaksa tingkah laku karyawannya yang bermasalah. Sikap seperti ini dapat menimbulkan perasaan ragu-ragu pada semua orang yang terlibat. Proses disiplin ini dapat digunakan sebagai sebuah kesempatan untuk membalik sebuah situasi yang bermasalah menjadi suatu yang menguntungkan semua pihak dan untuk mengubah perilaku sertta bukan untuk menghukum karyawan yang bermasalah. Kenyataannya sebagian karyawan perilakunya sesuai dengan harapan organisasi, dan sebagian lain yang perilakunya cukup diterima, namun ada pula beberapa karyawan yang sering menimbulkan masalah walaupun tidak semuanya seperti itu.

\section{Penelitian Terdahulu}

Runik Puji Rahayu (2010) melakukan penelitian dengan tujuan untuk mengetahui pengaruh motivasi kerja dan kepuasan kerja terhadap kinerja karyawan pada Universitas Madura dengan disiplin kerja sebagai variabel intervening. Penelitian ini dilakukan kepada seluruh karyawan kontrak maupun PNS dengan jumlah 70 orang dan metode sensus. Teknik analisis 
dilakukan dengan analisis jalur SPSS 19.00. Hasil penelitian menunjukkan bahwa variabel motivasi kerja dan kepuasan kerja berpengaruh signifikan positif terhadap disiplin kerja, variabel motivasi kerja dan kepuasan kerja berpengaruh signifikan positif terhadap kinerja dan variabel disiplin kerja dapat menjadi intervening antara variabel motivasi dan kepuasan kerja dengan kinerja karyawan Universitas Madura.Dengan nilai $\mathrm{R}^{2}$ pada model pertama sebesar 0,559 dan pada model kedua sebesar 0,621. Hal ini menunjukkan bahwa motivasi dan kepuasan kerja yang tinggi didukung oleh disiplin kerja akan menghasilkan kinerja karyawan yang bagus.

\section{Kerangka Teoritis}

Pada penelitian Runik Puji Rahayu (2010), motivasi kerja dan kepuasan kerja berpengaruh terhadap kinerjakaryawan Universitas Madura dengan disiplin kerja sebagai intervening. Kerangka teoritis penelitian ini adalah:

Gambar II-1

Kerangka Teoritis Penelitian

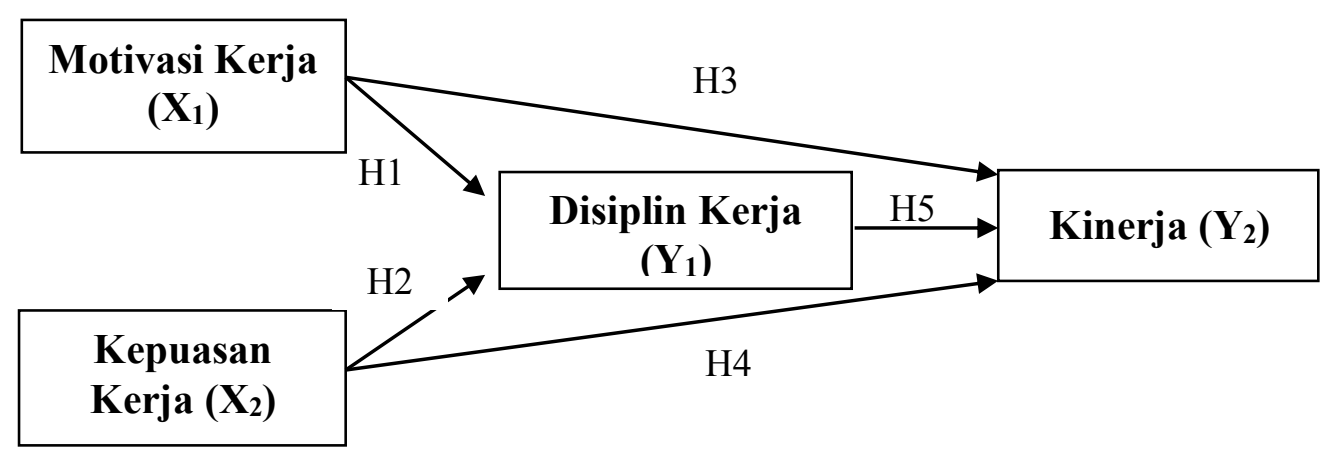

Sumber: Data Primer Diolah, 2015

H1 : Motivasi kerjaberpengaruh positif terhadapdisiplin kerjapegawai Dinas Tenaga Kerja, Transmigrasi dan Sosial (Disnakertransos) Kabupaten Kebumen

$\mathrm{H} 2$ :Kepuasan kerja berpengaruh terhadapdisiplin kerjapegawai Dinas Tenaga Kerja, Transmigrasi dan Sosial (Disnakertransos) Kabupaten Kebumen

H3 :Motivasi kerjaberpengaruh terhadapkinerjapegawai Dinas Tenaga Kerja, Transmigrasi dan Sosial (Disnakertransos) Kabupaten Kebumen

$\mathrm{H} 4$ :Kepuasan kerja berpengaruh terhadapkinerjapegawai Dinas Tenaga Kerja, Transmigrasi dan
Sosial (Disnakertransos) Kabupaten Kebumen

H5 :Disiplin kerjaberpengaruh terhadapkinerjapegawai Dinas Tenaga Kerja, Transmigrasi dan Sosial (Disnakertransos) Kabupaten Kebumen

\section{METODE PENELITIAN}

\section{Obyek dan Subyek Penelitian}

Obyek pada penelitian ini adalah variabel motivasi kerja dan kepuasan kerja sebagai variabel bebas, variabel disiplin kerja dan kinerja sebagai variabel terikat. Subyek dari penelitian adalah seluruh pegawai Dinas Tenaga Kerja, 
Transmigrasi dan Sosial (Disnakertransos) Kabupaten Kebumen.

\section{Variabel Penelitian dan Definisi}

\section{Operasional Variabel}

\section{Variabel Penelitian}

Variabel menurut Sugiyono (2008:42)merupakan gejala yang menjadi fokus untuk diamati oleh peneliti, sebagai atribut dari sekelompok orang atau objek yang mempunyai variasi antara satu dengan yang lainnya dalam kelompok tersebut. Variabel dalam penelitian ini terdiri atas :

a. Variabel Dependen
Variabel dependen merupakan variabel yang dipengaruhi atau menjadi akibat karena adanya variabel lain (variabel bebas). Variabel terikat dalam penelitian ini adalahdisiplin kerjadan kinerja.

b. Variabel Independen

$$
\text { Variabel independen adalah }
$$
variabel yang menjadi sebab atau berubahnya suatu variabel lain (variabel dependen).Variabel bebas penelitian ini adalah motivasi kerja dan kepuasan kerja.

c. Variabel Intervening

Variabel intervening adalah variabel antara yang menghubungkan variabel terikat dan variabel bebas. Dalam penelitian ini yang menjadi variabel intervening adalah disiplin kerja ( $Y_{1}$ ).

\section{Definisi Operasional Variabel}

\section{a. $\operatorname{Kinerja}\left(\mathrm{Y}_{2}\right)$}

Definisi secara konseptual kinerja merupakan tingkat keberhasilan dalam melaksanakan tugas dan kemampuan untuk mencapai tujuan yang telah ditetapkan. Sedangkan definisi operasional variabel kinerja adalah kemampuan seseorang dalam menyelesaikan pekerjaan dan biasanya diukur dengan prestasi yang telah ditetapkan pemerintah (Jahri, 2007;77). Adapun indikator kinerja adalah sbagai berikut :

Tabel III-1

Distribusi Indikator Kinerja $\left(\mathbf{Y}_{2}\right)$ pada Kuisioner

\begin{tabular}{|l|l|c|c|}
\hline \multicolumn{1}{|c|}{ No } & \multicolumn{1}{|c|}{ Indikator } & $\begin{array}{c}\text { Distribusi } \\
\text { butir ke }\end{array}$ & Jumlah \\
\hline 1. & Kualitas kerja & $1-2$ & 2 \\
2. & Ketepatan waktu & $3-4$ & 2 \\
3. & Inisiatif & $5-6$ & 2 \\
4. & Kemampuan & $7-8$ & 2 \\
5. & Komunikasi & $9-10$ & 2 \\
\hline
\end{tabular}

\section{Sumber: Data Primer Diolah, 2015}

b.Motivasi Kerja ( $\mathrm{X}_{1}$ )

Menurut Robbins dalam Sayuti (2006), menyebutkan bahwa pengukuran motivasi kerja dapat dilakukan dengan melihat pada beberapa aspek/indikator sebagai berikut :

Tabel III-2

Distribusi Indikator Motivasi Kerja (X1) pada Kuisioner

\begin{tabular}{|l|l|c|c|}
\hline No & \multicolumn{1}{|c|}{ Indikator } & $\begin{array}{c}\text { Distribusi } \\
\text { butir ke }\end{array}$ & Jumlah \\
\hline 1. & $\begin{array}{l}\text { Mempunyai sifat agresif } \\
\text { 2. }\end{array}$ & $\begin{array}{l}\text { Kreatif dalam melaksanakan } \\
\text { pekerjaan. }\end{array}$ & 2 \\
3. & Mutu pekerjaan meningkat dari & 3 & 1 \\
\hline
\end{tabular}




\begin{tabular}{|c|c|c|c|}
\hline & hari ke hari. & & \\
\hline 4. & Mematuhi jam kerja & 4 & 1 \\
\hline 5. & $\begin{array}{l}\text { Tugas yang diberikan dapat } \\
\text { diselesaikan dengan kemampuan }\end{array}$ & 5 & 1 \\
\hline 6. & $\begin{array}{l}\text { Inisiatif kerja yang tinggi dapat } \\
\text { mendorong pretasi kerja. }\end{array}$ & 6 & 1 \\
\hline 7. & Kesetiaan dan kejujuran & 7 & 1 \\
\hline 8. & $\begin{array}{l}\text { Terjalin hubungan kerja antara } \\
\text { karyawan dengan pimpinan. }\end{array}$ & 8 & 1 \\
\hline 9. & $\begin{array}{l}\text { Tercapainya tujuan perorangan } \\
\text { dan tujuan organisasi. }\end{array}$ & 9 & 1 \\
\hline 10. & $\begin{array}{l}\text { Menghasilkan informasi yang } \\
\text { akurat dan tepat }\end{array}$ & 10 & 1 \\
\hline
\end{tabular}

Sumber: Data Primer Diolah, 2015

c. Kepuasan Kerja $\left(\mathrm{X}_{2}\right)$

Luthans (2006) menjelaskan kepuasan kerja adalah kegembiraan atau sikap emosi positif yang berasal dari pengalaman kerja seseorang. Luthans menyatakan bahwa kepuasan kerja memiliki lima indikator yaitu kepuasan terhadap sifat pekerjaan itu sendiri, kepuasan terhadap gaji atau upah, kepuasan terhadap promosi jabatan, kepuasan terhadap pengawasan atasan dan kepuasan terhadap kelompok kerja atau tim kerja

Tabel. III-3

Distribusi Indikator Kepuasan Kerja ( $\mathrm{X}_{2}$ ) pada Kuisioner

\begin{tabular}{|l|l|c|c|}
\hline No & \multicolumn{1}{|c|}{ Indikator } & $\begin{array}{c}\text { Distribusi } \\
\text { butir ke }\end{array}$ & Jumlah \\
\hline 1. & Sifat pekerjaan itu sendiri & 1 & 1 \\
2. & Gaji & 2 & 1 \\
3. & Promosi & 3 & 1 \\
4. & Pengawasan & 4 & 1 \\
5. & Kelompok kerja & 5 & 1 \\
\hline
\end{tabular}

\section{Sumber: Data Primer Diolah, 2015}

d. Disiplin Kerja ( Y1 )

Disiplin adalah suatu keadaan tertib dimana seseorang atau sekelompok yang tergabung dalam organisasi tersebut berkehendak mematuhi dan menjalankan peraturan yang ada, baik yang tertulis maupun tidak tertulis Hasibuan (2008;19). Adapun indicator disiplin kerja menurut Soejono (2005) yaitu ;

\section{Tabel III-4}

Distribusi Indikator Disiplin Kerja ( $\left.\mathrm{Y}_{1}\right)$ pada Kuisioner

\begin{tabular}{|l|l|c|c|}
\hline No & \multicolumn{1}{|c|}{ Indikator } & $\begin{array}{c}\text { Distribusi } \\
\text { butir ke }\end{array}$ & Jumlah \\
\hline 1. & Ketepatan waktu & $1-2$ & 2 \\
2. & Menggunakan peralatan kantor yang baik & $3-4$ & 2 \\
3. & Tanggung jawab yang tinggi & $5-6$ & 2 \\
4. & Ketaatan terhadap aturan kantor & $7-8$ & 2 \\
\hline
\end{tabular}

Sumber: Data Primer Diolah, 2015 
Jenis Data

1. Data Primer

Data primer adalah data yang diperoleh secara langsung dari obyek penelitian yaitu dengan kuesioner.

2. Data Sekunder

Data yang diperoleh dari instansi dan lembaga yang terkait erat hubungannya dengan penelitian ini atau data yang diperoleh dengan cara membaca buku literatur.

\section{Teknik Pengumpulan Data}

1. Kuesioner

Kuesioner digunakan supaya responden mengisi daftar pernyataan yang tercantum dalam kuesioner sesuai persepsi masingmasing. Kategori persepsi yang digunakan dengan memakai skoring skala likert 4 kategori, yaitu: jika nilai jawaban responden sangat setuju (SS) memperoleh skor 4, jawaban setuju (S) memperoleh skor 3, jawaban tidak setuju (TS) memperoleh skor 2, dan jawaban sangat tidak setuju (STS) memperoleh skor 1.

2. Studi Pustaka

Studi pustaka merupakan cara pengumpulan data dengan sumber data dari buku pustaka, internet dan jurnal yang berhubungan dengan penelitian.

\section{Populasi dan Sampel Penelitian}

Populasi

Populasi adalah wilayah generalisasi yang mempunyai kualitas dan karakteristik tertentu yang ditetapkan oleh peneliti untuk dipelajari dan kemudian ditarik kesimpulannya (Sugiyono,2008:41).

Sampel

Sampel adalah sebagian dari populasi yang diambil sebagai responden(Sugiyono,2008:41).Teknik

sampling yang dipakai adalah sensus atau sampel jenuh, yaitu mengambil semua populasi sebagai sampel.

\section{Teknis Analisis Data Analisis Deskriptif}

Analisis deksriptif digunakan berdasarkan pandangan dan pemikiran secara teoritis yang disajikan dalam bentuk keterangan dan penjelasan yang sifatnya klasifikasi (Suharsimi, 2002:154). Analisis deskriptif pada penelitian ini menjabarkan tentang identitas responden dengan persentase tertentu.

\section{Analisis Statistika}

Analisis Statistika atau kuantitatif adalah metode analisis data dengan menggunakan angka-angka yang diperoleh dari pengolahan data melalui rumus yang tepat.Adapun analisis yang digunakan meliputi :

\section{Uji Validitas}

Validitas yaitu tingkat ketepatan dan kecermatan alat ukur dalam melakukan fungsi ukurannya (Suliyanto, 2005:77). Menurut Ghozali, (2006), Validitas digunakan untuk mengukur sah atau tidaknya suatu kuesioner, dikatakan valid jika pertanyaan pada kuesioner mampu untuk mengungkap sesuatu yang akan diukur oleh kuesioner tersebut. Untuk menguji validitas alat ukur penelitian, peneliti mnggunakan program SPSS For Windows version 18. Ditentukan derajat kebebasan adalah $(\mathrm{n}-\mathrm{k})$, dengan tingkat kepercayaan $95 \%$ atau $\alpha=0,05$. Ketentuan pengujian sebagai berikit :

a. Jika $\mathrm{r}$ hitung $>\mathrm{r}$ tabel, berarti item tersebut valid.

b. Jika $\mathrm{r}$ hitung $<\mathrm{t}$ tabel, berarti item tersebut tidak valid.

Jika ditemukan item-item yang tidak valid, maka item-item tersebut tidak digunakan sebagai alat ukur atau item tersebut diperbaiki sehinngga dapat valid sebagai alat ukur.

\section{Uji Reliabilitas}

Reliabilitas yaitu sejauh mana hasil suatu pengukuran dapat dipercaya (Suliyanto, 2005:78). Konsep reliabilitas menunjuk pada sejauh mana hasil pengukuran yang 
didapat apabila pengukuran dilakukan ulang pada kelompok subyek yang sama. Untuk mengathui tingkat reliabilitas adalah dengan cara membandingkan nilai $r$ tabel dengan nilai alpha dengan ketentuan jika $r$ alpha lebih besar dari $r$ tabel, maka dinyatakan reliable (Sugiyono, 2005:152). Sedangkan menurut Imam Ghozali (2008:333), suatu lembar koding dinyatakan reliable jika nilai crombach alpha lebih besar dari 0,6. Jika ada item yang tidak reliable, maka tidak digunakan sebagai alat ukur atau diperbaiki sehigga item tersebut dapat reliabel.

3. Uji Asumsi Klasik

a. Multikolinieritas

Uji asumsi ini bertujuan untuk menguji apakah ada model regresi ditentukan korelasi antar variabel independen. Ada tidaknya multikolinieritas dalam model regresi, dapat dideteksi dengan melihat (Ghozali, 2009:49):

1) Besaran VIF (Variance Inflation Factor) dan Tolerance.

Pedoman suatu model regresi yang bebas multikolinieritas adalah :

a) Mempunyai nilai VIF di sekitar angka 1

b) Mempunyai angka tolerance mendekati 1

2) Nilai toleransi $\leq 0,10$ atau sama dengan nilai $\mathrm{VIF} \geq$ tingkat koloneritas 0,95 .

b. Heteroskedastisitas

Pengujian ini dilakukan untuk menguji apakah dalam model regresi terjadi ketidaksamaan varian dan residual dari suatu pengamatan yang lain. Model regresi yang baik adalah apabila tidak terjadi heteroskedastisitas (varians yang berbeda). Deteksi adanya heteroskedastisitas adalah sebagai berikut (Ghozali, 2009:50):

1) Jika terdapat pola tertentu, seperti titik-titik pada grafik yang membentuk suatu pola tertentu, maka pola tersebut telah terjadi heteroskedastisitas sehingga model regresi tersebut tidak dapat digunakan.

2) Jika tidak terdapat pola yang jelas, serta titik-titik pada grafik menyebar diatas dan dibawah angka 0 (nol) pada sumbu $Y$, maka tidak terjadi heteroskedastisitas, sehingga model regresi tersebut dapat digunakan.

c. Normalitas

Pengujian ini dilakukan untuk mengetahui apakah dalam sebuah regresi variabel dependen, variabel independen, atau keduanya, mempunyai distribusi normal atau tidak.Model regresi yang baik adalah distribusi normal atau mendekati normal. Suatu regresi dianggap normal apabila (Ghozali, 2009:51):

1) Jika data menyebar disekitar garis diagonal dan mengikuti arah garis diagonal, maka model regresi tersebut memenuhi asumsi normalitas.

2) Jika data menyebar jauh dari garis diagonal atau tidak mengikuti arah garis diagonal, maka model regresi tersebut tidak memenuhi asumsi normalitas.

\section{Analisis Jalur (Path Analysis)}

Menurut Suliyanto (2005: 59) analisis jalur merupakan perluasan dari analisis regresi linier berganda dimana penggunaan analisis regresi adalah untuk menaksir hubungan kausalitas antar variabel (model kasual) yang ditetapkan sebelumnya berdasarkan teori. Analisis jalur sendiri tidak dapat digunakan substitusi bagi peneliti untuk melihat hubungan kausalitas antar variabel.Apa yang dapat dilakukan oleh analisis jalur adalah menentukan pola hubungan antara tiga atau lebih variabel dan tidak dapat digunakan untuk mengkonfirmasi atau menolak hipotesis kausalitas imajiner. Analisis jalur dalam pengujian ini dilakukan untuk mengetahui kinerja ( $\mathrm{Y} 2$ ) terhadap motivasi ( X1), kepuasan 
kerja (X2), dan disiplin kerja (Y1), maka dapat digunakan rumus :

$\mathrm{Y}_{1}=\mathrm{PY}_{1} \mathrm{X}_{1}+\mathrm{PY}_{1} \mathrm{X}_{2}+€_{1}$ sebagai persamaan struktural 1

$\mathrm{Y}_{2}=\mathrm{PY}_{2} \mathrm{X}_{1}+\mathrm{PY}_{2} \mathrm{X}_{2}+\mathrm{PY}_{2} \mathrm{Y}_{1}+€_{2}$ sebagai persamaan struktural 2

Dimana :

$\mathrm{X}_{1}=$ Motivasi

$\mathrm{X}_{2}=$ Kepuasan Kerja

$\mathrm{Y}_{1}=$ Disiplin Kerja

$\mathrm{Y}_{2}=$ Kinerja

$€_{1}, €_{2}=$ Error

Untuk penghitungan pengaruh antar variabel secara langsung dan tidak langsung adalah sebagai berikut

a. Pengaruh Langsung (Direct Effect atau DE ).

Untuk menghitung pengaruh langsung atau DE, digunakan formula sebagai berikut :

- Pengaruh variabel Motivasi Kerja terhadap Disiplin kerja $\mathrm{X}_{1} \rightarrow \mathrm{Y}_{1}$

- Pengaruh variabel Kepuasan kerja terhadap Disiplin kerja $\mathrm{X}_{2} \longrightarrow \mathrm{Y}_{1}$

- Pengaruh variabel Motivasi kerja terhadap Kinerja $\mathrm{X}_{1} \rightarrow \mathrm{Y}_{2}$

- Pengaruh variabel Kepuasan kerja terhadap Kinerja $\mathrm{X}_{2} \longrightarrow \mathrm{Y}_{2}$

- Pengaruh variabel Disiplin kerja terhadap Kinerja $\mathrm{Y}_{1} \longrightarrow \mathrm{Y}_{2}$

b. Pengaruh tidak langsung ( Indirect effect atau IE)

Untuk menghitung pengaruh tidak langsung atau IE, digunakan formula sebagai berikut :
- Pengaruh variabel

Motivasi kerja

terhadap Kinerja

Pegawai melalui

Disiplin kerja.

$\mathrm{X}_{1} \rightarrow \quad \rightarrow \mathrm{Y}_{1}$

$\mathrm{Y}_{2}$

- Pengaruh variabel

Kepuasan kerja

terhadap Kinerja

pegawai melalui

Disiplin kerja

$\mathrm{X}_{2} \rightarrow \mathrm{Y}_{1} \rightarrow \mathrm{Y}_{2}$

c. Pengaruh Total Total effect )

- Pengaruh variabel

Motivasi Kerja

terhadap Kinerja

pegawai melalui

Disiplin kerja

$\mathrm{X}_{1} \rightarrow \mathrm{Y}_{1} \rightarrow \mathrm{Y}_{2}$

- Pengaruh variabel

Kepuasan Kerja

terhadap Kinerja

pegawai melalui

Disiplin kerja

$\mathrm{X}_{2} \rightarrow \mathrm{Y}_{1} \rightarrow \mathrm{Y}_{2}$

- Pengaruh variabel

Motivasi Kerja

terhadap Kinerja

pegawai

$\mathrm{X}_{1} \rightarrow \mathrm{Y}_{2}$

- Pengaruh variabel

Kepuasan Kerja

terhadap Kinerja

Pegawai

$\mathrm{X}_{2} \rightarrow \mathrm{Y}_{2}$

- Pengaruh variabel

Disiplin Kerja

terhadap Kinerja

Pegawai

$\mathrm{Y}_{1} \longrightarrow \mathrm{Y}_{2}$

\section{Analisis Korelasi}

Menurut Jonathan Sarwono (2005:77), analisis korelasi digunakan untuk mengetahui besaran korelasi antar variabel. Apabila angka korelasi bernilai antara $0-0,25$ dapat diartikan 
bahwa korelasi antar variabel sangat lemah atau harus dianggap tidak ada, angka korelasi $>0,25-0,5$ dapat diartikan bahwa korelasi antar variabel cukup, angka korelasi $>0,5-$ 0,75 artinya dapat dikatakan bahwa korelasi antar variabel kuat, angka korelasi $>0,75-1$ dapat diartikan bahwa korelasi antar variabel sangat kuat.

\section{HASIL ANALISIS DAN PEMBAHASAN}

\section{Analisis Statistika}

Analisis statistika ini dilakukan dengan menguji butir hasil tabulasi kuesioner yang telah diisi responden. Analisis ini dilakukan dengan melakukan pengujian berikut :

\section{Uji Validitas}

Kuesioner dinyatakan valid apabila pernyataan yang diajukan pada kuesioner tersebut mampu mengungkap sesuatu yang akan diukur pada kuesioner tersebut. Untuk mengukur validitas digunakan Product Momentpada angka corrected item total correlation SPSS 18, dengan degree of freedom $45(\mathrm{df}=\mathrm{n}-2=47-2)$, maka $\mathrm{r}$ tabel sebesar 0,294.

1. Variabel Motivasi Kerja $\left(\mathrm{X}_{1}\right)$

Hasil uji validitasvariabel motivasi kerjadijelaskan sebagai berikut:

\section{Tabel IV-6}

Hasil Uji Validitas Variabel Motivasi kerja

\begin{tabular}{|c|r|r|c|}
\hline Butir & r hitung & r tabel & Status \\
\hline 1 & 0,549 & 0,294 & Valid \\
\hline 2 & 0,548 & 0,294 & Valid \\
\hline 3 & 0,513 & 0,294 & Valid \\
\hline 4 & 0,498 & 0,294 & Valid \\
\hline 5 & 0,489 & 0,294 & Valid \\
\hline 6 & 0,464 & 0,294 & Valid \\
\hline 7 & 0,668 & 0,294 & Valid \\
\hline 8 & 0,659 & 0,294 & Valid \\
\hline 9 & 0,388 & 0,294 & Valid \\
\hline 10 & 0,665 & 0,294 & Valid \\
\hline
\end{tabular}

Sumber : Data Primer Diolah, 2015

Dari tabel diatas dapat dijelaskan bahwa $r$ hitung lebih besar dari $r$ tabel, sehingga variabelmotivasi kerjadinyatakan valid (syah).

1. Variabel Kepuasan $\operatorname{Kerja}\left(\mathrm{X}_{2}\right)$

Hasil uji validitas variabel kepuasan kerjadijelaskan pada tabel berikut ini:

Tabel IV-7

Hasil Uji Validitas Variabel Kepuasan kerja

\begin{tabular}{|c|r|r|c|}
\hline Butir & $\mathrm{r}$ hitung & $\mathrm{r}$ tabel & Status \\
\hline 1 & 0,566 & 0,294 & Valid \\
\hline 2 & 0,402 & 0,294 & Valid \\
\hline 3 & 0,533 & 0,294 & Valid \\
\hline 4 & 0,593 & 0,294 & Valid \\
\hline 5 & 0,626 & 0,294 & Valid \\
\hline
\end{tabular}

Sumber : Data Primer Diolah, 2015 
Sesuai dengan tabel diatas, maka semua item pernyataan yang dipakai pada variabel kepuasan kerjadinyatakan valid (syah), karena $r$ hitung lebih besar $r$ tabel.

3. Variabel Disiplin $\operatorname{Kerja}\left(\mathrm{Y}_{1}\right)$

Hasil uji validitas variabel disiplin kerja dapat dijelaskansebagai berikut:

Tabel IV-8

Hasil Uji Validitas Variabel Disiplin kerja

Sumber : Data Primer Diolah, 2015

\begin{tabular}{|c|r|r|c|}
\hline Butir & Rhitung & \multicolumn{1}{c|}{$\mathrm{r}$ tabel } & Status \\
\hline 1 & 0,566 & 0,294 & Valid \\
\hline 2 & 0,592 & 0,294 & Valid \\
\hline 3 & 0,534 & 0,294 & Valid \\
\hline 4 & 0,711 & 0,294 & Valid \\
\hline 5 & 0,688 & 0,294 & Valid \\
\hline 6 & 0,616 & 0,294 & Valid \\
\hline 7 & 0,520 & 0,294 & Valid \\
\hline 8 & 0,393 & 0,294 & Valid \\
\hline
\end{tabular}

Dari tabel diatas dapat dijelaskan bahwa $r$ hitung lebih besar dari $r$ tabel, sehingga semua item pernyataan yang dipakai pada variabel disiplin kerjadinyatakan valid (syah).

4. Variabel Kinerja $\left(\mathrm{Y}_{2}\right)$

Hasil uji validitas variabel kinerja sebagai berikut:

Tabel IV-9

Hasil Uji Validitas Variabel Kinerja

\begin{tabular}{|c|r|r|c|}
\hline Butir & R hitung & r tabel & Status \\
\hline 1 & 0,703 & 0,294 & Valid \\
\hline 2 & 0,720 & 0,294 & Valid \\
\hline 3 & 0,610 & 0,294 & Valid \\
\hline 4 & 0,538 & 0,294 & Valid \\
\hline 5 & 0,727 & 0,294 & Valid \\
\hline 6 & 0,655 & 0,294 & Valid \\
\hline 7 & 0,689 & 0,294 & Valid \\
\hline 8 & 0,638 & 0,294 & Valid \\
\hline 9 & 0,533 & 0,294 & Valid \\
\hline 10 & 0,658 & 0,294 & Valid \\
\hline
\end{tabular}

Sumber : Data Primer Diolah, 2015

Dari tabel diatas dapat dijelaskan bahwa $r$ hitung lebih besar dari $r$ tabel, sehingga semua item pernyataan yang dipakai pada variabel kinerja dinyatakan valid (syah).

\section{Uji Reliabilitas}

Uji reliabilitas butir dilakukan dengan ketentuan, jika $r$ alpha $\geq 0,6$, maka variabel tersebut reliabel dan sebaliknya jika $r$ alpha $<0,6$, maka variabel tersebut tidak reliabel.

Tabel IV-10

Hasil Uji ReliabilitasVariabel

\begin{tabular}{|l|c|c|c|}
\hline \multicolumn{1}{|c|}{ Variabel } & $\mathrm{r}$ alpha & Nilai Minimal & Status \\
\hline Motivasi kerja & 0,846 & 0,6 & Reliabel \\
\hline Kepuasan kerja & 0,764 & 0,6 & Reliabel \\
\hline Disiplin kerja & 0,839 & 0,6 & Reliabel \\
\hline
\end{tabular}




\begin{tabular}{|l|c|c|c|}
\hline \multicolumn{1}{|c|}{ Variabel } & r alpha & Nilai Minimal & Status \\
\hline Motivasi kerja & 0,846 & 0,6 & Reliabel \\
\hline Kepuasan kerja & 0,764 & 0,6 & Reliabel \\
\hline Kinerja & 0,897 & 0,6 & Reliabel \\
\hline
\end{tabular}

Sumber : Data Primer Diolah, 2015

Berdasarkan tabel diatas, hasil analisis dapat dijelaskan bahwa seluruh variabel yang dipakai dalam penelitian ini dinyatakan reliabel (andal) karena $r$ alphanya lebih besar dari 0,6 .

\section{Uji Asumsi Klasik}

Uji asumsi klasik terbagi menjadi 3, yaitu:

\section{Uji Multikolinieritas}

Hasil uji mulikolinearitas dapat dilihat pada tabel berikut :

Tabel IV-11

Uji Multikolinearitas Persamaan struktural I

\section{Coefficients $^{\mathrm{a}}$}

\begin{tabular}{|c|c|c|}
\hline \multirow{2}{*}{ Model } & \multicolumn{2}{|c|}{$\begin{array}{c}\text { Collinearity } \\
\text { Statistics }\end{array}$} \\
\cline { 2 - 3 } & $\begin{array}{c}\text { Toleranc } \\
\mathrm{e}\end{array}$ & \multicolumn{1}{c|}{ VIF } \\
\hline $\begin{array}{l}\text { (Constant) } \\
\text { MOTIVASI KERJA }\end{array}$ & .475 & 2.105 \\
\hline $\begin{array}{l}\text { KEPUASAN } \\
\text { KERJA }\end{array}$ & .475 & 2.105 \\
\hline
\end{tabular}

a. Dependent Variable: DISIPLIN KERJA

Sumber : Data Primer Diolah, 2015

Berdasarkan tabel coefficients di atas dapat dijelaskan bahwa pada bagian collinearity statistic menunjukan bahwa VIF dibawah 10 dan tolerancedi atas 0,1 . Karena itu model regresipersamaan strukturalI ini tidak terdapat multikolinieritas, sehingga model regresi dapat dipakai.

Tabel IV-12

Uji Multikolinearitas Persamaan struktural II

\section{Coefficients ${ }^{\mathrm{a}}$}

\begin{tabular}{|l|r|r|}
\hline \multirow{2}{*}{ Model } & \multicolumn{2}{|c|}{ Collinearity Statistics } \\
\cline { 2 - 3 } & Tolerance & \multicolumn{1}{c|}{ VIF } \\
\hline 1 (Constant) & .294 & 3.401 \\
MOTIVASI & & \\
KERJA & .466 & 2.147 \\
\hline $\begin{array}{l}\text { KEPUASAN } \\
\text { KERJA }\end{array}$ & & \\
\hline DISIPLIN KERJA & .374 & 2.673 \\
\hline
\end{tabular}

a. Dependent Variable: KINERJA

Sumber : Data Primer Diolah, 2015

Berdasarkan tabel coefficients di atas dapat dijelaskan bahwa pada bagian collinearity statistic menunjukan bahwa angka VIF dibawah 10 dan tolerancedi atas 0,1 . 
Karena itu model regresi persamaan strukturalII ini tidak terdapat multikolinieritas, sehingga model regresi dapat dipakai.

\section{Uji Heterokedastisitas}

Pengujian ini dilakukan untuk menguji apakah dalam sebuah model regresi terjadi ketidaksamaan varian dan residual disatu pengamatan ke pengamatan yang lain. Hasil analisis diperoleh sebagai berikut :

\section{Gambar IV-2 \\ Uji HeterokedastisitasPersamaan struktural I}

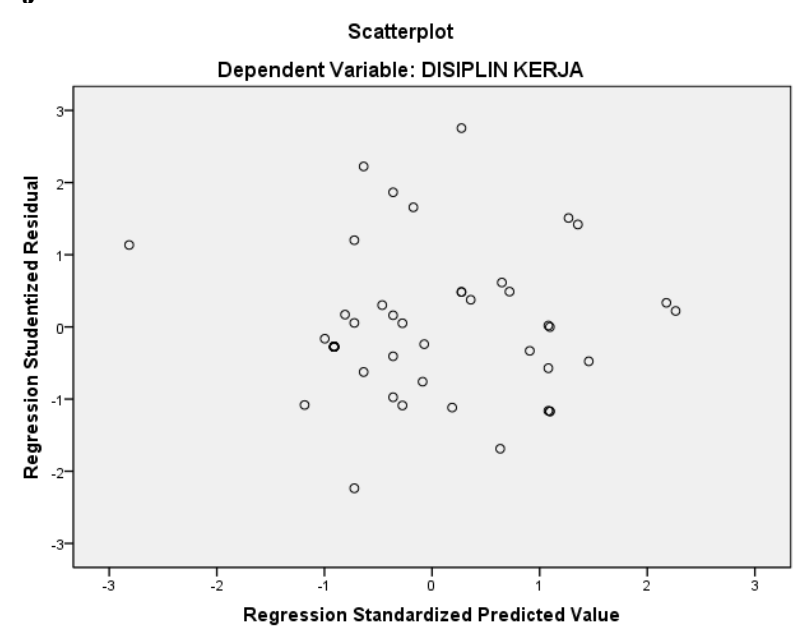

Sumber : Data Primer Diolah, 2015

Berdasarkan gambar grafik di atas, menunjukan bahwa tidak ada pola tertentu, seperti titik-titik yang membentuk suatu pola tertentu yang teratur (bergelombang, melebar, kemudian menyempit) dan tidak ada pola yang jelas sehingga dapat disimpulkan model regresi Persamaan struktural I dalam penelitian ini tidak terjadi heterokedastisitas.

\section{Gambar IV-3 \\ Uji HeterokedastisitasPersamaan struktural II}

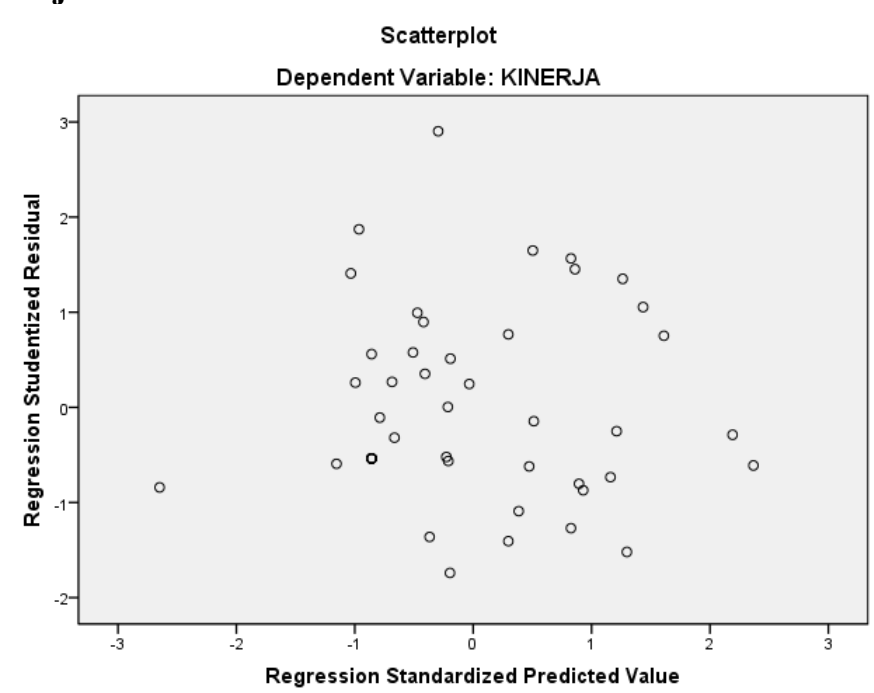

Sumber : Data Primer Diolah, 2015

Berdasarkan gambar grafik di atas, menunjukan bahwa tidak ada pola tertentu, seperti titik-titik yang membentuk suatu pola tertentu yang teratur (bergelombang, melebar, kemudian menyempit) dan tidak ada pola yang jelas sehingga dapat disimpulkan model regresi Persamaan struktural II dalam penelitian ini tidak terjadi heterokedastisitas. 


\section{Uji Normalitas}

Analisis ini untuk menguji apakah data sebuah model regresi, antara variabel dependen dan variabel independen/ keduanya mempunyai distribusi normal/mendekati normal.

\section{Gambar IV-4}

\section{Uji Normalitas Persamaan struktural I}

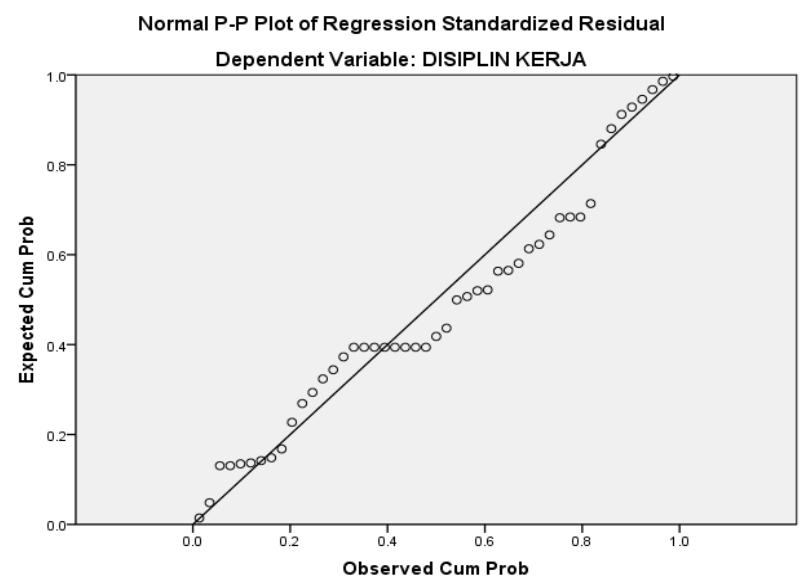

Sumber : Data Primer Diolah, 2015

Berdasarkan gambar grafik uji normalitas terlihat bahwa data menyebar disekitar garis diagonal dan mengikuti arah garis diagonal. Maka model regresi memenuhi asumsi normalitas.

\section{Gambar IV-5}

\section{Uji Normalitas Persamaan struktural II}

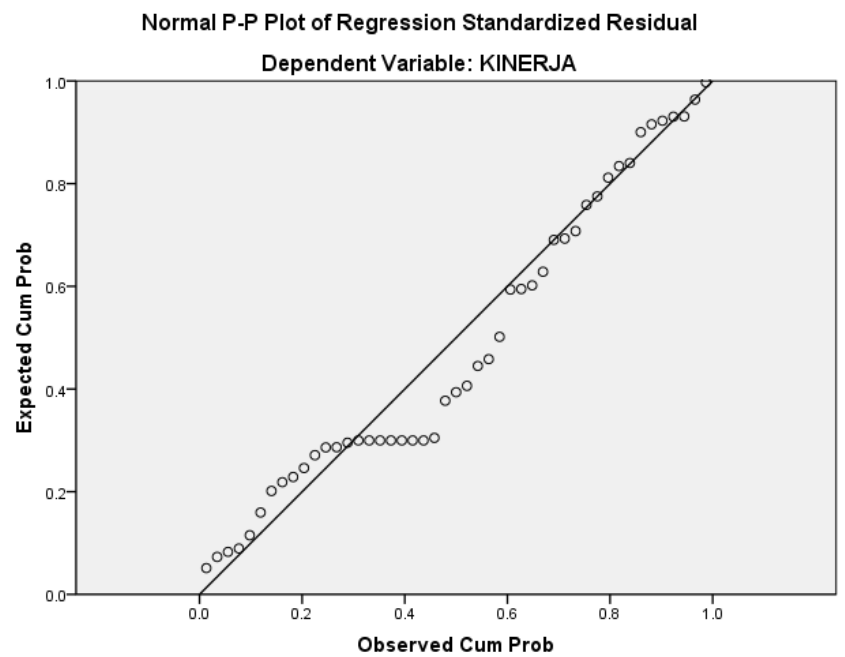

Sumber : Data Primer Diolah, 2015

Berdasarkan gambar grafik uji normalitas terlihat bahwa data menyebar disekitar garis diagonal dan mengikuti arah garis diagonal. Maka model regresi memenuhi asumsi normalitas.

\section{KESIMPULAN}

1. Motivasi kerja berpengaruh terhadap disiplin kerja pegawai Dinas TenagaKerja, Transmigrasi dan Sosial Kabupaten Kebumen. Hal ini motivasi dapat meningktakan disiplin kerja pegawai Disnakertransos.

2. Kepuasan kerja tidak mempunyai pengaruh terhadap disiplin kerja pegawai Dinas Tenaga Kerja, 
Transmigrasi dan Sosial Kabupaten Kebumen. Hal ini kepuasan kerja tidak dapat menurunkan kinerja pegawai Disnakertransos.

3. Motivasi kerja berpengaruh signifikan terhadap kinerja pegawai Dinas TenagaKerja, Transmigrasi dan Sosial Kabupaten Kebumen. Hal ini motivasi dapat meningkatkan kinerja pegawai Disnakertransos.

4. Kepuasan kerja berpengaruh terhadap kinerja pegawai Dinas Tenaga Kerja,
Transmigrai dan Sosial Kabupaten Kebumen. Hal ini kepuasan kerja dapat meningkatkan kinerja pegawai Disnakertransos.

5. Disiplin kerja bernilai positif maka mempunyai pengaruh terhadap kinerja pegawai Disnakertransos Kabupaten Kebumen. Hal ini disiplin kerja dapat meningkatkan kinerja pegawai Disnakertransos sebesar $12,7 \%$.

\section{DAFTAR PUSTAKA}

As'ad, Moh. 2003. Psikologi Industri. Yogyakarta: Penerbit Liberty

Arikunto, Suharsimi. 2002. Prosedur Penelitian: Suatu Pendekatan Praktik, Edisi Revisi. Yogyakarta:Graha Ilmu

Data Primer Disnakertransos Kabupaten Kabupaten Kebumen Tahun 2014

Davis, O.A and Larkey, P.D. 1996.Measuring the Efficiency and Effectiveness of Government Activities, from Improving the Financial Discipline of State and Cities (terjemah). Jakarta: Prenhallindo

Dessler, Garry. 2007. Human Resources Management, Jilid 2 (Terjemah). Jakarta: PT Prenhallindo

Sayuti. 2006 Motivasi dan faktor-faktor yang mempengaruhi.Jakarta : Ghalia Indonesia.

Runik Puji Rahayu, SE. 2010. Pengaruh Motivasi, Kepuasan Keja dan Disiplin Kerja Terhadap Kinerja Karyawan di Universitas Madura Pamekasan, Tesis Pasca Sarjana (tidak dipublikasikan), Jember : Manajemen Universitas Jember.

Dharma, Surya. 2005. Manajemen Kinerja: Falsafah, Teori dan Penerapannya.Jakarta: Pustaka Pelajar

Ghozali, Imam. 2009. Aplikasi Analisis Multivariate Dengan Program SPSS, Cetakan SSKeempat. Semarang:Badan Penerbit Universitas Diponegoro

Hadi, Sutrisno. 2004. Metodologi Riset Jilid II. Yogyakarta: Penerbit Andi Offset

Hasibuan, Malayu P. 2009. ManajemenSumberDayaManusia. Jakarta:SalembaEmpat

Kartono, Kartini. 2004. ManajemenKinerjaEdisi 2. Jakarta: PenerbitSalemba

Mahmudi. 2005. ManajemenKinerjaSektorPublik. Yogyakarta:AkademiManajemen Perusahaan YKPN

Mangkunegara, Anwar Prabu. 2000. Manajemen Sumber Daya Manusia Perusahaan.Bandung:Penerbit Rosdakarya

Mathis, RL dan Jackson JH. 2002. Human resources Management: Essential Perspectives. 2nd Edition.(Terjemahan). South Western Cincinnati: $\mathrm{OH}$ Division of Thompson Learning

Nawawi, Hadari. 2008. PeningkatanKinerjaKaryawan. Bandung: PenerbitAlfabeta

Nitisemito, Alex S. 2006. ManajemenPersonalia. Jakarta: PenerbitGhalia Indonesia

PP Nomor 46 Tahun 2011 TentangPenilaianPrestasiKerjaPegawaiNegeriSipil

Rahayu, Runik Puji. 2010.Pengaruh Motivasi Kerja Dan Kepuasan Kerja Terhadap Kinerja

Karyawan Pada Universitas Madura Dengan Disiplin Kerja Sebagai Variabel Intervening. Madura: Universitas Madura

Rivai, Veithzal. 2006. Performance Appraisal (Terjemahan). Bandung: Rajawali Press 
Robbin, S. 2006.Organizational Behaviour, Concept, Controversie, Application. Seventh Editions.Prentice Hall Inc. New South Wales

Sarwono, Jonathan. 2004. Analisis Jalur untuk Riset Bisnis dengan SPSS: Aplikasi dalam Riset Pemasaran, Keuangan, Manajemen Sumber Daya Manusia dan Kewirausahaan. Bandung: PenerbitAndi

Sugiyono. 2008. Metode Penelitian Administrasi. Bandung: Penerbit Alfabeta

Vivi dan Rorlen.2007. PengaruhIklim Organisasi Dan Kedewasaan Terhadap Kinerja \begin{tabular}{lllllll} 
Karyawan PT Graha Tungki Arsitekta Jakarta.JurnalBundaMulia & Vol. 03 \\
\hline
\end{tabular} No.01.Jakarta: Universitas Indonesia

Widayat.2009. AnalisisFaktor-faktor Yang MempengaruhiKepuasanKerjaPegawai (StudiKasuspada UPTD Panti Tuna LarasNgudiRahayu Kendal).Semarang:FE Unes (Tidakdipublikasikan)

Wiyantoro, Candra Eko. 2014. Pengaruh Kepemimpinan Transformasional Dan Motivasi Terhadap Peningkatan Kinerja Karyawan Dengan Disiplin Kerja Kariawan Sebagai Variabel Intervening Pada Kantor Pariwisata dan Kebudayaan Kabupaten Jember. Jember: Universitas Jember

Widoso, DS. 2001. Kepemimpinan dan Motivasi. Jakarta: Ghalia Indonesia

Wursanto.1990. PolaKepemimpinan yang Efektif. Jakarta: RinnekaCipta 